\title{
III. Bemerkung.
}

Von

Prof. Dr. P. Baumgarten, Königsberg i. Pr.

In seinem Aufsatze: „Neue Mittlıeilungen über die Patlıgenie der acuten allgemeinen Milıartuberculose" (d. Bl. No. 24) äussert Weig ert, dass er mein Nachweisungsverfahren der Tuberkel bacillen in phthisischen Sputis deshalb niclıt empfehlen könne, weil es nicht gestalte, die Vortheile, die der Abbe'sche Apparat mit vollem Strahlenkegel bietet, auszunützen; ausserdem widerspräche dasselbe einenı Hauptgrundsatz der hustologischen Technik, spärliche und kleine Gebilde dunkel auf hellem Grunde erschieinen zu lassen, und nicht umgekelırt.

Ich kann zu meinem Bedauern diese Ausführungen Weigert's nıcht unwiderlegt lassen. Was den ersten Punkt betrifft, so habe ich es gerade als einen Vorzug meiner Metlode hingestellt, dass sie es ermöglichı, die Tuberkelbacillen, selbst in vereinzelten Exemplaren, auclı ohne Anwendung der Immersionssysteme und des Abbe'schen Beleuchtungsapparates, mit voller Deutlıclıkeit, und zwar in ihrem natürlichen Zustande, zu selıen (wıe es überlıaupt bei mir histologisclıer Grundsatz ist, die Objecte möglichst in threr natürlichen Erscheinung zur Anschauung zu bringen). Die Verdeckung der Bacillen durch Gewebskerne, auf welche Weigert als ein nur durch intensive Färbung und Durchleuchtung zu besiegendes Hillderniss der Erkennung hinweisst, kommt für meine Methode nicht in Betracht, da durch dieselbe alle Gewebskerne unsichtbar gemacht werden. Iclı kann dalıer den ersten Einwurf Weigert's gegen meine Metlode nicht als stichhaltig anerkennen. Was nun zweitens die Bemerkung anlangt, dass nıein Verfahreı einem Hauptgrundsatz der histologischen Technik widerspräche, so liegt derselben, glaube ich, ein Missverständniss Seitens Weig ert's zu Grunde. Mene Methode der Darstellung der Tuberkelbacillen ist keine andere, als die für bakteriologische Untersuchungen altb ewährte Kalimethode, die niemals einem Grundsatz der histologischen Technik widersprochen hat und auch lieute enem solchen niclit widerspricht. Wenn ich zu Sputumpräparaten, in welchen dıe darin vorhandenen Tuberkelbacillen durch Kalıbehandlung sichtbar gemacht sind, Farbstofflösung in der von niir beschriebenen Weise hinzufüge, so geschielit dies nicht der Tuberkel-, sondern der etwa im Präparate mitvorhandenen Fäulnıss- resp. Mundschleımbacillen wegell, um diese letzteren, welchıe sofort den Farbstoff begierig aufnelınıen von den Tuberkelbacillen, welche, ilır natürliches Aussehen bewalırend, vollkommen farblos bleiben, mit Sichıerheit zu differenziren. Dıe Färbung des Untergrundes spielt dabei in diagnostischer Hinsicht keine Rolle; je besser die Präparate, d. h. je dünner und gleichmässiger die zu untersuchenden Schicliten sind, desto lieller kann die Farbstnfflösung genommen, und somit die Untergrundsfärbıng eingeschıränkt resp. (für die mikroskopische Betrachttung) auf Null reducirt werden. 